\title{
ENTRE CHAMAS E LÁGRIMAS: A REALIDADE DE UMA BIBLIOTECA
}

\author{
Sandra Daniele Haugg Fernandes \\ Universidade de Caxias do Sul \\ sdhf1414@gmail.com
}

Resumo

\begin{abstract}
Este trabalho visa apresentar a realidade de funcionamento da Biblioteca Pública Prof Elsa Hofstätter da Silva, de Nova Petrópolis. Serão apresentados os serviços disponíveis, as atividades desenvolvidas, o conteúdo do acervo e a atuação de profissionais na instituição. Esta Biblioteca, sem fins lucrativos, foi criada em mil, novecentos e noventa e recebeu esse nome para homenagear a Dona Elsa, autora do Hino de Nova Petrópolis, poetisa e teatróloga. Possuía, em média, vinte e cinco mil livros registrados. Estavam inclusos neste acervo, variados gêneros literários, coleções infantojuvenis, coleções especiais escritas em língua estrangeira, periódicos atualizados, além de jornais locais e regionais e revistas em quadrinhos. A biblioteca tem quatro mil e setecentos leitores cadastrados. Em 2011 a Biblioteca passou por um incêndio que abalou suas estruturas físicas e seu acervo, resultando em um prejuízo imensurável.
\end{abstract}

Palavras-chave: Biblioteca. Acervo. Incêndio.

$\mathbf{1}$
$\mathbf{I}$
$\mathbf{N}$
$\mathbf{T}$
$\mathbf{R}$
$\mathbf{O}$
$\mathbf{D}$
$\mathbf{U}$
$\mathbf{C}$
$\tilde{\mathbf{A}}$
$\mathbf{O}$

O presente trabalho em formato de relato de experiência visa relatar fatos reais sobre um sinistro que permeia à história da Biblioteca Pública Municipal Prof ${ }^{a}$ Elsa Hofstätter da Silva, sita à Rua Tiradentes, $\mathrm{n}^{\circ} 256$, no centro da cidade de Nova Petrópolis, no Estado do Rio Grande do Sul/RS. Foi pesquisado o antes e o depois do incêndio, como era a biblioteca e como ela ficou. $\mathrm{O}$ acervo anterior e o que restou dele. $\mathrm{O}$ mobiliário perdido $\mathrm{e} a$ reconstrução de um novo espaço.

A minha motivação em escrever este artigo foi o tempo em que trabalhei nesta unidade de informação como funcionária e a vivência que passei a cada momento difícil deste incêndio. Da mesma forma, pretendo demonstrar como foi gratificante o sentimento de viver um novo recomeço. Com isto penso em verificar se a maneira utilizada para recomeçar foram realmente as mais sensatas. E analisar novamente o processo reavaliando-o sob uma nova perspectiva.

As providências tomadas foram corretas? E o recomeço, foi conforme esperado? Este é o tema do artigo que trataremos a seguir. Um desafio ao reescrever uma história que teve seu rumo mudado repentinamente em função de um terrível incêndio.

Para melhor entendimento o artigo estará dividido em seis partes: Conceito de Biblioteca Pública, Histórico da Instituição, Acervo da Biblioteca, Atividades Desenvolvidas, Serviços Oferecidos pela Instituição e a História do Incêndio.

\section{CONCEITO DE BIBLIOTECA PÚBLICA}

Por ser uma Unidade de Informação, a Biblioteca Pública tem a missão de atender a toda a comunidade proporcionando igualdade de acesso a todos, sejam homens ou mulheres, negros ou brancos, jovens, crianças ou adultos. Como diz o nome é um ambiente público e assim deve ser acolhedor e incentivador para troca de ideias, experiências e vivências de cada um que a frequenta.

O seu principal foco de atuação da biblioteca pública é o incentivo à leitura e a 
busca por assuntos dos mais variados que cativem a sua clientela. Esta unidade de informação pode ser vinculada a prefeituras, estados ou à União, sendo essas bibliotecas nomeadas como Municipal, Estadual ou Nacional. Considera-se que "A biblioteca pública é o espaço privilegiado do desenvolvimento das práticas leitoras, e através do encontro do leitor com o livro forma-se o leitor crítico e contribui-se para o florescimento da cidadania." (Biblioteca Nacional, 2000, p. 17)

Assim, podemos dizer que a biblioteca pública tem como missão, incentivar à leitura, criar leitores críticos, selecionar a informação, permitir o livre acesso ao acervo, ser o elo de comunicação entre usuário e o mundo do conhecimento. Com este intuito a biblioteca visa atender a todos os tipos de leitores e ofertar a eles a bibliografia adequada, de acordo com a faixa etária e o conhecimento de cada um. O bibliotecário é interlocutor desta história. Cabe a ele ser o mediador entre a leitura e o seu leitor. Isso só torna-se possível quando o material procurado está registrado, catalogado e organizado conforme necessário. Para um bom trabalho, basta seguir as leis de Ranganatham, onde ele nos traz que $\left(1^{\mathrm{a}}\right)$ os livros são para usar, $\left(2^{\mathrm{a}}\right)$ que cada pessoa tem o seu livro, $\left(3^{\mathrm{a}}\right)$ que cada livro tem o seu leitor, $\left(4^{a}\right)$ que devemos poupar o tempo do leitor e $\left(5^{\mathrm{a}}\right)$ que a biblioteca é um organismo em crescimento.

Desta forma, torna-se então, necessário, despertar nos Bibliotecários, a busca por dados específicos que tragam aos leitores formas de acesso às mais diversas informações. Definindo, a partir deste novo paradigma, um sistema de unidade mais crítico e de melhoria contínua, proporcionando o encantamento dos leitores e expressando a importância da atualização.

\section{HISTÓRICO DA INSTITUIÇÃO}

A Biblioteca Pública Municipal Prof ${ }^{a}$ Elsa Hofstätter da Silva está localizada em de Nova Petrópolis/RS, uma bela cidade, tranquila e acolhedora, encantando os olhos de todos que por ela passam. Tem hoje, em torno de vinte mil habitantes e leva o título de Jardim da Serra Gaúcha pela sua beleza exuberante e paisagem surpreendente. É conhecida ainda como a Capital Nacional do Cooperativismo, por ser o berço do cooperativismo de crédito na América Latina e tendo sediado a primeira cooperativa de crédito em 1902.

Em 1979, o então Prefeito de Nova Petrópolis, Sr. Ewaldo Michaelsen, promulgou a Lei ${ }^{\circ} 655$, de 19 de agosto de 1979, a qual criava a Biblioteca Pública Municipal e a denominava "Érico Veríssimo".

Onze anos se passaram e foi sancionada então, pelo Prefeito Augusto Schranck Junior, a Lei $\mathrm{n}^{\circ} 1.192$, de 26 de julho de 1990. Esta Lei, no seu Art. $1^{\circ}$, cria a Biblioteca Pública Municipal, com a denominação de Prof $^{a}$ Elsa Hofstätter da Silva. E no seu Art. $2^{\circ}$, revoga a Lei $\mathrm{n}^{\circ} 655$, de 19 de agosto de 1979. Até o presente momento, a Biblioteca criada, através desta última Lei, ainda não tinha sido construída. Por este motivo acredita-se que a mesma foi novamente criada através de outra Lei para homenagear a Dona Elsa, (conforme Figura 1), a qual foi, além de professora, poetisa, teatróloga e a autora do Hino de Nova Petrópolis.

\section{Figura 1 - Prof ${ }^{a}$ Elsa Hofstätter da Silva}

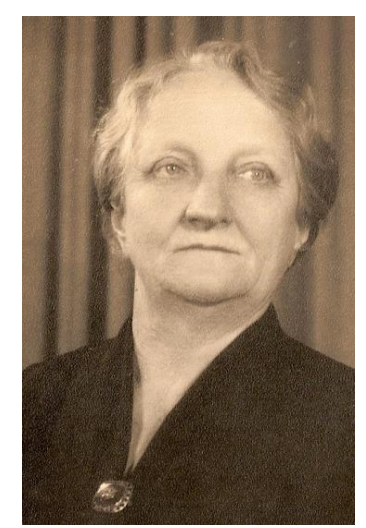

Fonte: Biblioteca Pública Municipal Prof ${ }^{a}$ Elsa Hofstätter da Silva. 
A Biblioteca então criada pela Lei de 1990 foi inaugurada no dia 27 de fevereiro de 1994, tendo como missão básica, criar e fortalecer o gosto pela leitura, promover o conhecimento da herança cultural e garantir acesso aos cidadãos a todo tipo de informação de interesse da comunidade.

\section{ACERVO DA BIBLIOTECA}

A Biblioteca Pública Municipal possuía em seu acervo, até o sonistro que será aqui relatado, cerca de vinte e cinco mil obras, entre livros, revistas, gibis e jornais. Dentre o acervo existente, podíamos listar: jornais locais (como, A Ponte, Jornal de Nova Petrópolis, Nossa Terra e O Diário) e regionais (como Correio do Povo, NH, Pioneiro e Zero Hora), revistas Veja e Super Interessante, por assinatura e Isto É, Caras, História, Terra, entre outras, por doação. Existia uma imensa variedade de gibis, doações da Turma Disney e assinatura da Mônica, Magali, Cebolinha, Cascão, Chico Bento, Ronaldinho Gaúcho e Turma da Mônica Jovem (as quais tinham ótima circulação).

E quanto aos livros... Que rico acervo era disponibilizado! Usando a tabela CDU (Classificação Decimal Universal), a biblioteca apresentava uma grande diversidade nos mais variados assuntos. Tínhamos, inclusive, muitas obras de referência, dicionários, enciclopédias, almanaques, guias e Guinness. E o setor mais procurado sempre era o de literatura, para todas as idades. As obras preferidas eram as infantis de Monteiro Lobato, Léia Cassol, Ziraldo e Maurício de Sousa. Nas obras infantojuvenis, destacavamse Júlio Verne, J. K. Rowling, R. L. Stine e Meg Cabot. E os romances, ficavam por conta de Nora Roberts, Danielle Steel, Machado de Assis, Gabriel García Márquez e Ane Rice. A Figura 2 apresenta parte da estrutura da biblioteca:

Figura 2 - Acervo de Literatura

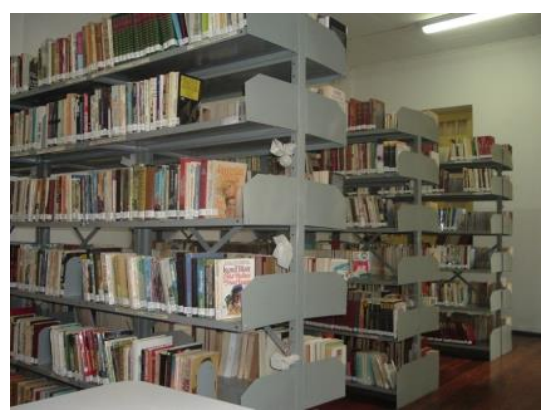

Fonte: Acervo Pessoal

As obras eram obtidas, na maioria das vezes, sob a forma de doação. Algumas apenas que provinham de compras. Outra forma de aquisição de acervo era a permuta, ou seja, fazíamos a troca de obras repetidas por outras que ainda não tínhamos.

\section{ATIVIDADES DESENVOLVIDAS}

A equipe de trabalho era composta por diretora, bibliotecária, auxiliar de biblioteca e auxiliar de serviços gerais. Antes do incêndio, esta equipe da Biblioteca Pública Prof ${ }^{a}$ Elsa Hofstätter da Silva, mantinha uma série de atividades durante o ano, entre elas o dia 27 de fevereiro, na qual se comemora o aniversário da biblioteca. Hoje, felizmente, a maioria delas voltou a ser realizada. A seguir apresento algumas delas:

\subsection{AULAS DE LÍNGUA ALEMÃ E TCHECO}

Eram ministradas aulas de Língua Alemã e Língua Tcheca, com assessoramento da equipe da biblioteca a alunos e professores, com o objetivo de preservar a cultura alemã e boêmia trazida pelos nossos antepassados.

\subsection{DIA MUNICIPAL DE INCENTIVO À LEITURA E DE SEUS MEDIADORES}

Em março, no dia 12, se comemora no município de Nova Petrópolis, o "Dia Municipal de Incentivo à Leitura e de seus Mediadores". Esta data é reconhecida legalmente, através de um decreto público municipal e foi escolhida em virtude de ser o Dia do Bibliotecário.

Nesta data, então, a Biblioteca Pública funcionava junto à Rua Coberta durante todo o 
dia, conforme mostra a Figura 3, recebendo cadastrando novos leitores.

devoluções, realizando empréstimos e

Figura 3 - Biblioteca montada junto à Rua Coberta

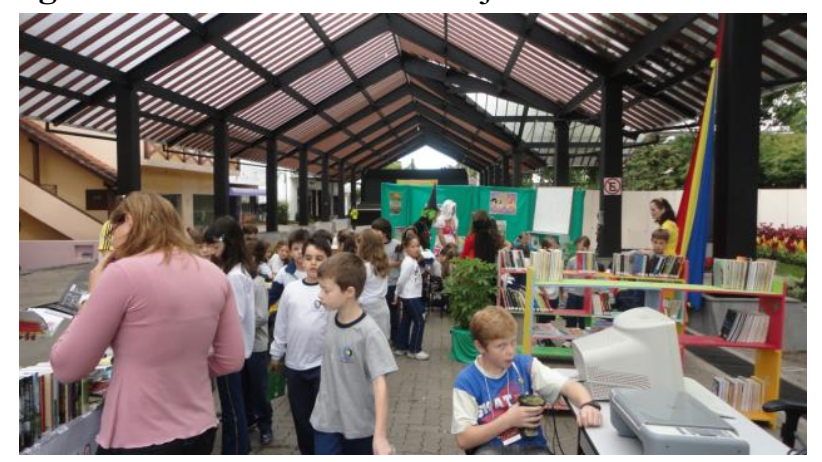

Fonte: Acervo Pessoal

Havia ainda a Feira do Troca-troca, como mostra a Figura 4, onde, durante o atendimento ao público, quem quisesse, poderia trazer um livro e trocar por outro de sua preferência.

Figura 4 - Feira do Troca-troca

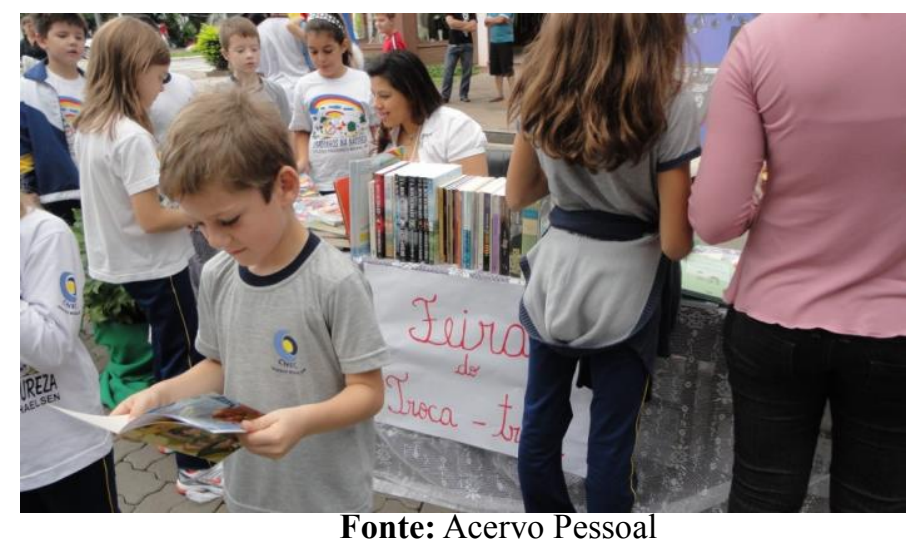

$\mathrm{Na}$ Estação Rodoviária do município, jovens voluntários fizeram, no interior dos ônibus, a ação de ler uma mensagem aos passageiros, assim como a entrega de um marcador de páginas a cada um deles. Durante a semana, mensagens foram lidas em português e alemão, aos idosos em visita aos Lares de Idosos da cidade, como mostra a Figura 5.

Figura 5 - Leitura para os idosos no Lar Lydia Braun

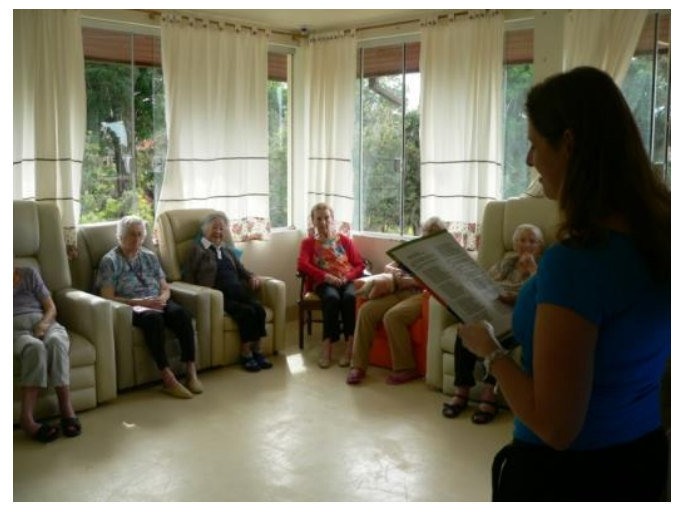

Fonte: Acervo Pessoal 
Houve ainda no decorrer da semana, a distribuição de exemplares de livros em algumas residências no centro, conforme Figura 6. Dentro destes livros existiam mensagens explicando sobre o dia 12 de março, o que é, para que serve e também tinha uma explicação de que quem gostaria de trocar seu exemplar por outra obra, era só ir à Feira do Troca-troca.

Figura 6 - Entregando livros em uma residência

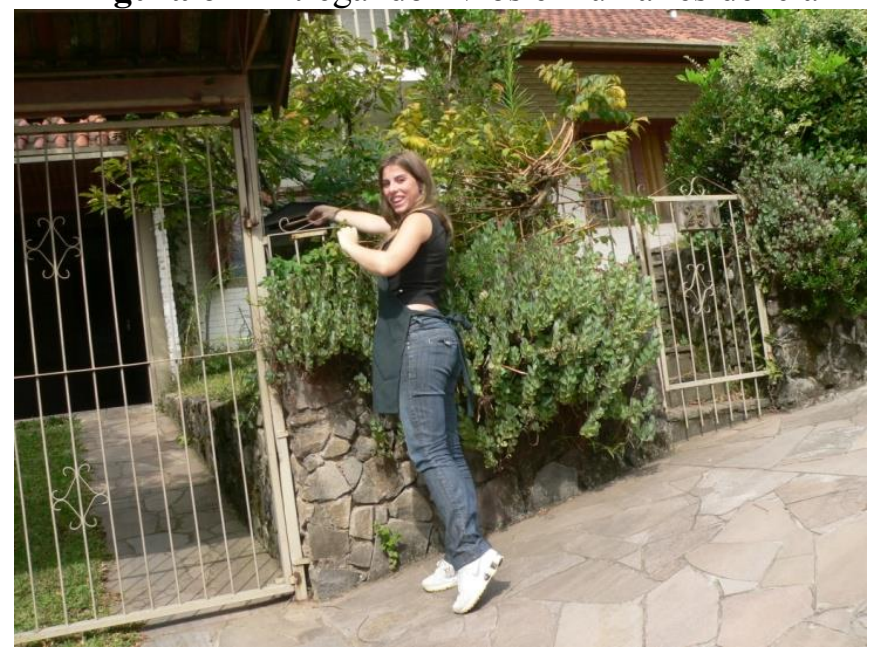

Fonte: Acervo Pessoal

Durante o dia 12 de março, as pessoas que viessem trajadas com uma fantasia de algum personagem, de qualquer história, poderiam deixar com a equipe da biblioteca seu nome e contato, para concorrer, no final do dia, a um livro sorteado entre os participantes. Houve uma "parada na sinaleira", conforme Figura 7, onde a cada momento que a sinaleira fechasse, dois voluntários abriam na rua uma faixa mostrando que era dia 12 de março, o "Dia Municipal de Incentivo à Leitura e de seus Mediadores".

Figura 7 - "Parada na sinaleira"

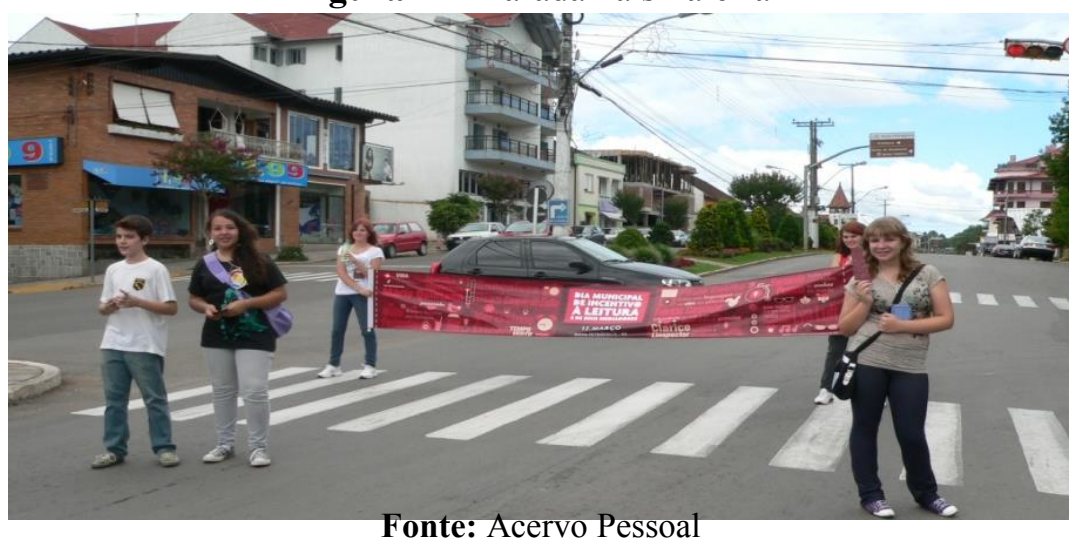

Durante a semana que antecedeu o dia 12 de março, voluntários realizaram Horas do Conto nas escolas e também na Rua Coberta. Mais voluntários divulgaram o dia, através da entrega de marcadores de páginas, junto ao comércio local da cidade.

\subsection{SEMANA DO LIVRO}

Durante o mês de abril, ocorria a Semana do Livro, conforme mostram as Figuras 8 e 9. Esta atividade era realizada com alunos dos sextos anos da rede municipal e estadual de ensino, objetivando incentivá-los a conhecer novos autores e a fortificar nestes o hábito de leitura. 
Figuras 8 e 9 - Semana do Livro no Colégio Frederico Michaelsen
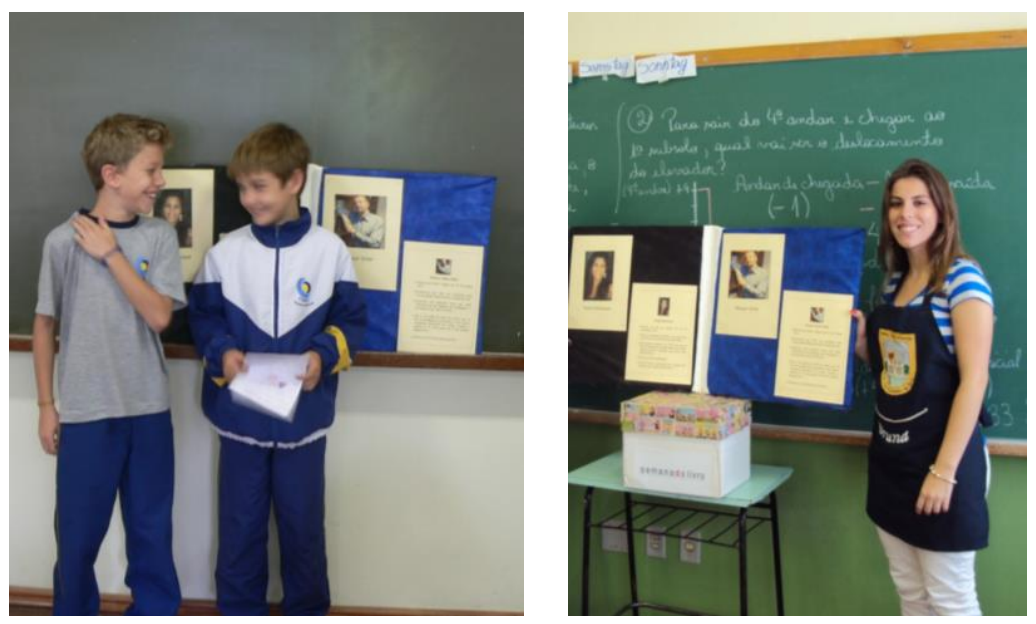

Fonte: Biblioteca Pública Municipal Prof ${ }^{a}$ Elsa Hofstätter da Silva

\subsection{DORMINDO COM OS LIVROS}

Em maio realizávamos o Dormindo com os Livros, como mostra a Figura 10. Esta atividade era direcionada a crianças, entre seis e onze anos. Elas participavam de atividades durante a noite, como hora do conto, teatro, jogos e atividades lúdicas. Depois jantavam e, literalmente, dormiam entre os livros. $\mathrm{Na}$ manhã seguinte, tomavam café da manhã na biblioteca e recebiam um mimo por sua participação na atividade.

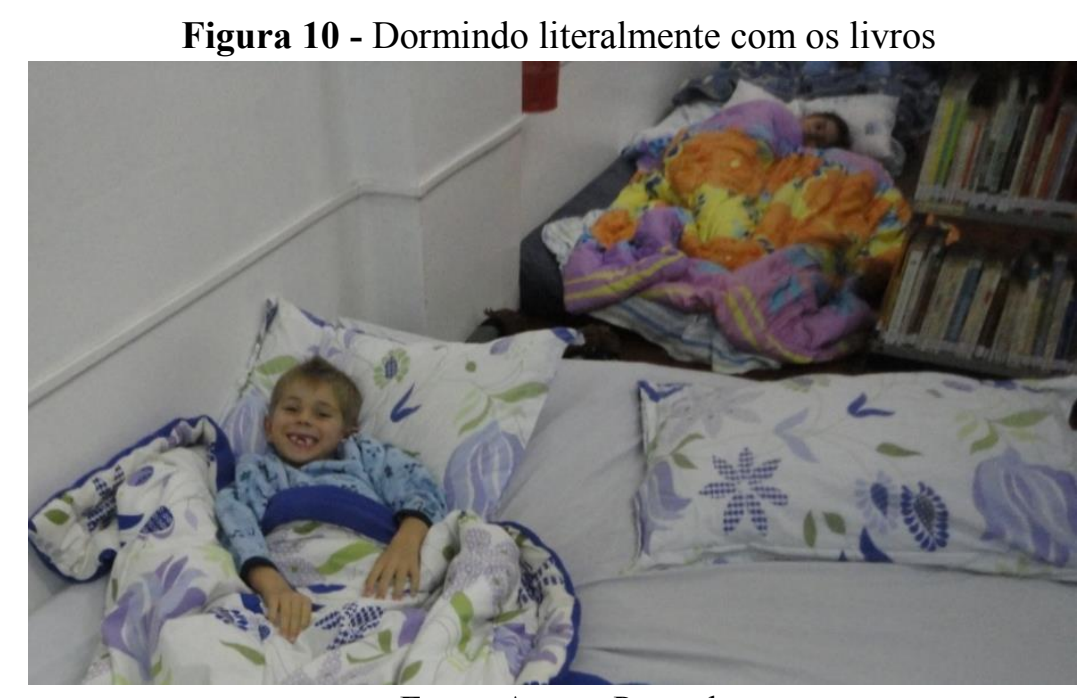

Fonte: Acervo Pessoal

\subsection{LITERATURA COMENTADA}

Em maio, em julho e em setembro ocorria a Literatura Comentada. Esse evento trazia, a cada momento, um novo tema. O público-alvo desta atividade eram os adultos, sendo que, a cada encontro, discutíamos assuntos da atualidade ou outros em que surgiam dúvidas ou sugestões.

Dentre os encontros realizados foram trazidos poetas do município para falarem de suas obras e foram também convidados autores dos livros da história de Nova Petrópolis para falarem sobre seu trabalho. Noutra oportunidade trouxemos o Centro de Tradições Gaúchas, o CTG Pousada da Serra para falarem sobre Lendas do Sul. Trouxemos um escritor de literatura infantil, em especial, história em quadrinhos para explanar os bastidores deste mundo encantador que é a literatura. E, na Figura 11 aparece o encontro com uma psicóloga, a qual tratou sobre o tema "O papel do psicólogo e do psicopedagogo nos dias de hoje".

As bibliotecas, em especial as públicas, devem não só atender às demandas, mas 
também criar demandas. A criação de demandas não significa que elas serão impostas. A ideia aqui presente é a de possibilitar condições de contato da comunidade com situações desconhecidas por ela, é dar oportunidade para que os usuários conheçam e se aproximem de realidades que não fazem parte de sua prática cotidiana ou que, apesar de algumas vezes serem conhecidas, não são consideradas como pertinentes ou adequadas para eles. A avaliação deve ser realizada de forma diferenciada para cada biblioteca. Se as demandas são específicas, a avaliação ou avaliações também serão (ALMEIDA JUNIOR, 2003, p. 204)

Figura 11 - Literatura Comentada realizada pela Biblioteca Pública

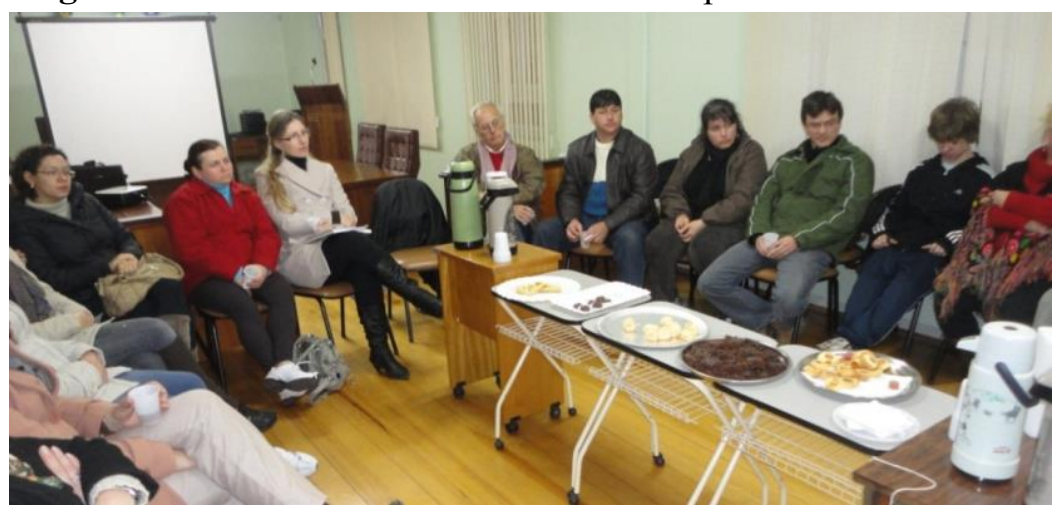

Fonte: Acervo Pessoal

\subsection{SEMANA DO MEIO AMBIENTE}

Em junho, era realizado durante a Semana do Meio Ambiente, o evento, "Doe um livro, adote uma planta", onde se fazia esta troca que beneficiaria, tanto a Biblioteca, como o leitor em busca da preservação da natureza.

\subsection{EXPOSIÇÃO DE OBRAS DE ARTISTAS LOCAIS}

Em agosto, havia na instituição, a Exposição de Obras de Artistas Locais, onde estes eram convidados a exporem os seus trabalhos, como pintura de quadros, artesanato ou até mesmo, trabalhos escolares. Sendo esta uma forma de incentivar os artesãos, artistas plásticos, pintores e até mesmo alunos a demonstrarem seus trabalhos à comunidade.

\subsection{SEMANA DA PÁTRIA}

Durante a Semana da Pátria, em setembro, a Biblioteca participava da programação alusiva à data, dando sua contribuição, junto ao palco da Rua Coberta, durante os momentos de Hora Cívica, organizados pela Secretaria Municipal de Educação.

\subsection{OLIMPÍADA DE LITERATURA INFANTIL}

Em outubro ocorria a Olimpíada de Literatura Infantil, conforme as Figuras 12, 13 e 14. Este evento trazia à biblioteca, cerca de setecentas crianças de três a seis anos, as quais vinham à instituição e, além de conhecer suas dependências, também assistiam a um teatro, geralmente interpretado pelas próprias funcionárias.

Figura 12 - Encenação da história: "Os Três Porquinhos"

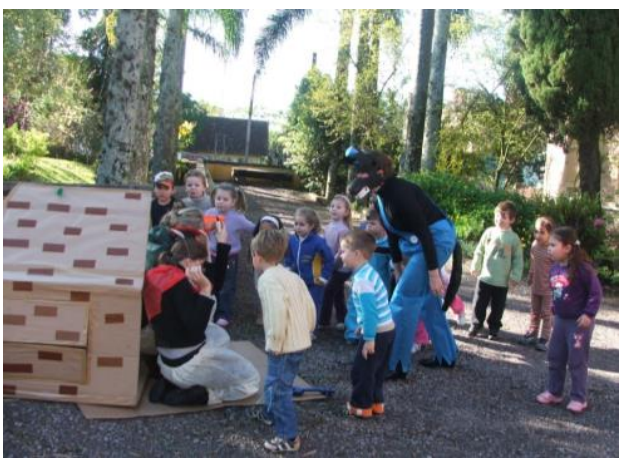


Fonte: Acervo Pessoal

Figura 13 - Encenação da história: "João e Maria"

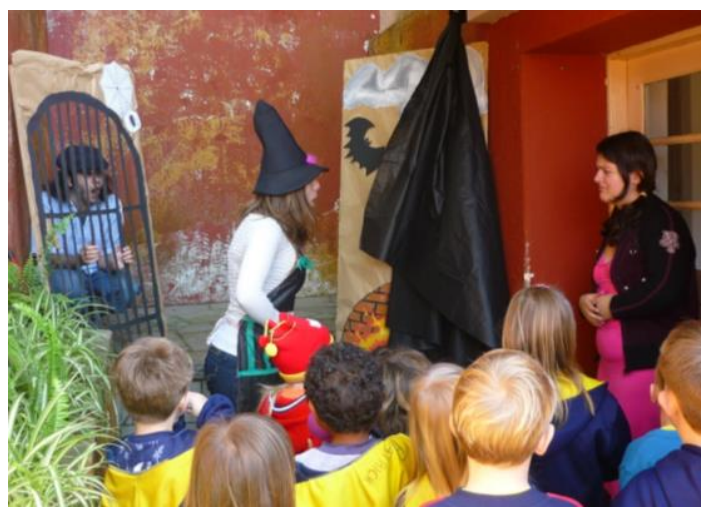

Fonte: Acervo Pessoal

Figura 14 - Entrega de medalhas a todos os participantes do evento

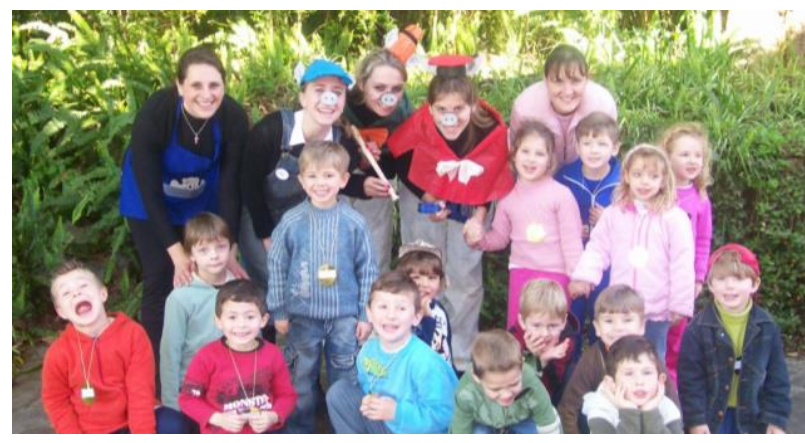

Fonte: Acervo Pessoal

Esta atividade era e é de suma importância, pois é de pequeno que as crianças absorvem mais facilmente o mundo encantador da literatura. Pois, "ensinar não é transferir conhecimento, mas criar as possibilidades para a sua produção ou a sua construção". (Freire, 2002, p.12).

\subsection{SARAU LITERÁRIO}

Em novembro acontecia o Sarau Literário entre os alunos da Língua Alemã e Tcheca. Esta atividade tinha como objetivo oportunizar aos alunos compartilhar suas experiências e aprendizagens obtidas durante o ano letivo, a todos os colegas e professores de ambas as turmas.

\section{SERVIÇOS OFERECIDOS PELA INSTITUIÇÃO}

Além de todas as atividades citadas anteriormente, também existiam outros serviços prestados pela Biblioteca Pública. O atendimento ao público e o cadastramento dos usuários junto à biblioteca, são exemplo disto.
Fazia-se ainda, a operação de sistema de empréstimo, devolução, reserva e renovação. A ordenação e a guarda do material da biblioteca em seus próprios lugares. A informação aos usuários sobre os serviços disponíveis e as normas de empréstimo. $\mathrm{O}$ atendimento $\mathrm{e}$ a orientação aos usuários da biblioteca. $\mathrm{O}$ fornecimento do material para consulta ou leitura no recinto da biblioteca. $\mathrm{O}$ zelo pela obediência ao regulamento da instituição. O cálculo, recebimento e depósito do valor das multas cobradas.

Existia ainda o processamento técnico, a preparação do material para empréstimo e circulação. A digitação de entrada de dados no sistema informatizado. E o cadastro dos leitores no mesmo. Fazia-se a coleta de dados estatísticos referentes ao empréstimo diário dos materiais e às consultas locais.

Era feito o processamento técnico do material incorporado ao acervo: catalogação, classificação e indexação.

Semanalmente era enviada uma "Dica de Leitura" para a coluna de variedades do jornal local, Jornal Nossa Terra e enviada 
mensalmente uma "Dica de Leitura" para a Rádio Inova FM, também no município. E para

\section{HISTÓRIA DO INCÊNDIO}

7.1 AFLIÇÃO NA COMUNIDADE NOVAPETROPOLITANA

O prédio onde hoje está localizada a o jornal local, Jornal A Ponte, era feito o envio quinzenal do "Leitor Destaque".

Biblioteca Pública foi construído em 1937, conforme vemos na Figura 15. Nesta foto vêse a parte dos fundos, quase no término de sua construção.

Figura 15 - Construção do Colégio Evangélico em 1937

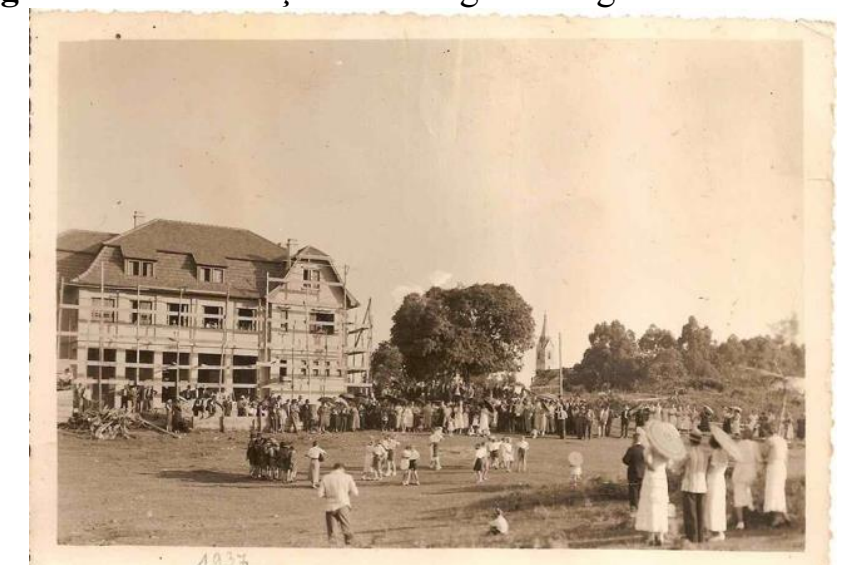

Fonte: Comunidade do Facebook > Fotografias Históricas de Nova Petrópolis

$\mathrm{Na}$ época foi ali instalado o Colégio Evangélico, o qual foi destinado a dar uma educação um pouco além das escolas comunitárias, sendo que tinha internato, masculino e feminino. Não somente alunos da cidade frequentavam a instituição, mas também alunos das redondezas, como Feliz, Galópolis e Caxias do Sul.

Este prédio tem muita história, por ele já passaram muitas coisas, entre elas, Hospital, APAE, Hotel, Escola Cenecista, Assistência Social, Lions Club, Câmara de Vereadores, Fundação Cultural, Arquivo Histórico e, em 1937, o já citado, Colégio Evangélico.
No ano de 1939, na madrugada do dia 22 de setembro, o primeiro e mais triste incêndio do prédio. Segundo relatos, o início do sinistro foi pelas seis e quarenta e cinco da manhã. A provável causa foi à falta de energia elétrica $\mathrm{e}$ uma vela acesa deixada pelas camareiras do internato do colégio, que haviam levantado para fazer o café. O incêndio começou na parte superior do prédio, nas mansardas, como se pode ver na Figura 16, no dormitório dos alunos.

Figura 16 - Vista frontal e vista das mansardas do prédio

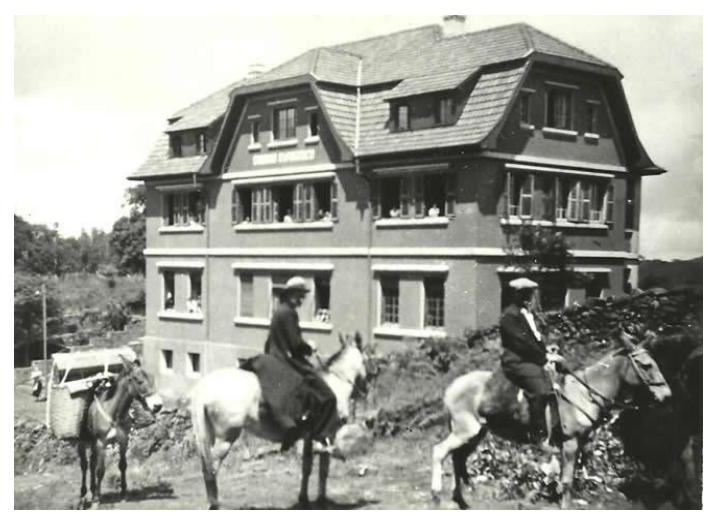

Fonte: Site da Câmara de Vereadores de Nova Petrópolis 
O fogo destruiu praticamente por completo

19. o prédio, conforme vemos nas Figuras 17, $18 \mathrm{e}$

Figura 17 - Cenas do início do incêndio do prédio

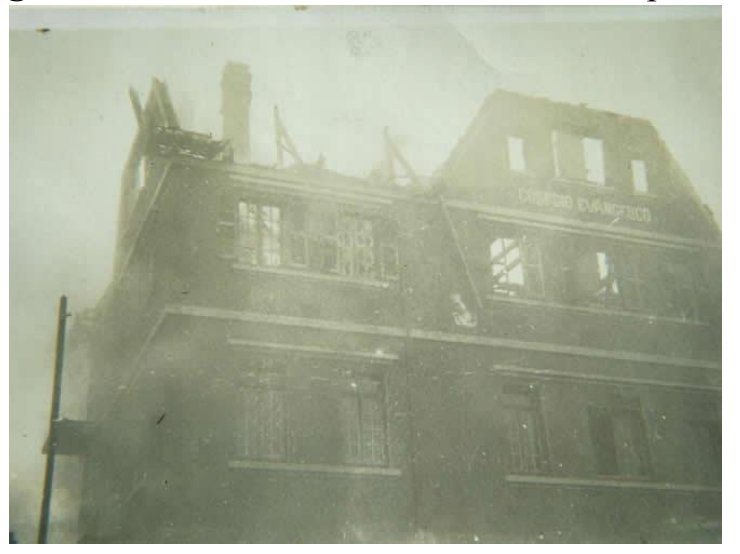

Fonte: Site da Câmara de Vereadores de Nova Petrópolis

Figura 18: Comunidade entristecida com o incêndio

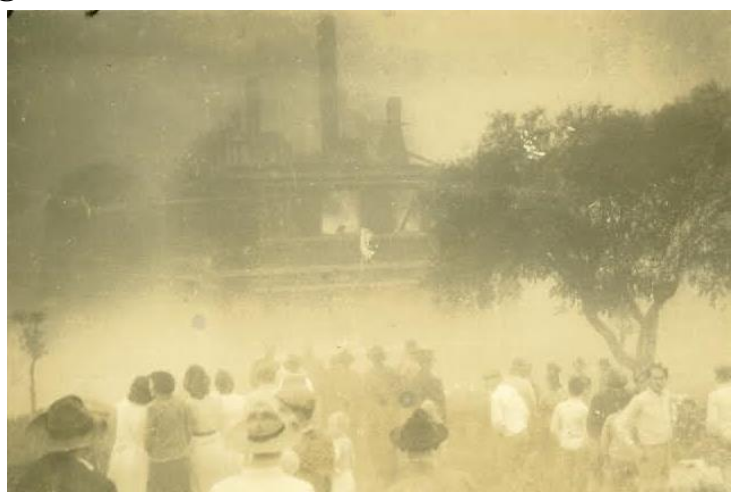

Fonte: Arquivo Histórico de Nova Petrópolis

Figura 19: Parede frontal do prédio durante o sinistro

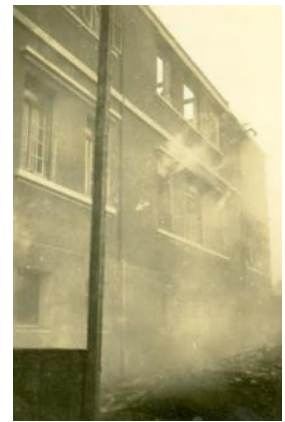

Fonte: Arquivo Histórico de Nova Petrópolis

Um aluno avistou casualmente o fogo ao se levantar para ir ao banheiro. Percebeu o incêndio por uma fresta da sala da rouparia. Isto permitiu salvar os demais estudantes que estavam pelos dormitórios. As chamas eram enormes e tomaram rapidamente quase todo o prédio. Restaram apenas algumas partes de estrutura das paredes no térreo do prédio, conforme nos mostra a Figura 20. 


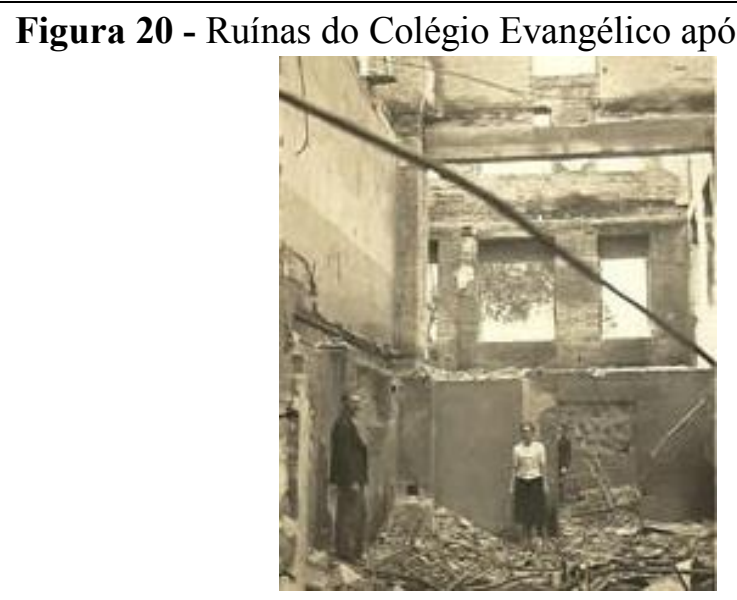

Fonte: Site da Câmara de Vereadores de Nova Petrópolis

Diante de tamanha aflição, houve a mobilidade de toda a comunidade, a qual se reuniu e se empenhou na reconstrução de um novo prédio. Este ficou muito parecido com o modelo original.

\subsection{OUTRA MANCHA NA HISTÓRIA}

Em 2008, o prédio sofreu outro sinistro. $\mathrm{Na}$ época estavam instalados no prédio, a Biblioteca Pública, a Câmara de Vereadores e o Arquivo Histórico. O fogo iniciou no segundo andar do prédio, o qual abrigava a Câmara de Vereadores. Houve um curtocircuito na parte elétrica daquele andar. $\mathrm{Na}$ ocasião, perdeu-se em torno de vinte livros que foram atingidos com a água que desceu pelas paredes, do segundo para o primeiro andar. A parte atingida do segundo piso ficou praticamente toda destruída, mas felizmente a parte da Biblioteca pouco sofreu.

\subsection{ENTRE CHAMAS E LÁGRIMAS}

Sábado pela manhã, das oito às onze horas, a biblioteca sempre estava aberta ao público. Porém, numa triste manhã, esta realidade mudou completamente. Era 4 de junho de 2011, mais uma vez, talvez por casualidade, as seis e quarenta e cinco da manhã... Outro sinistro!

Porém, desta vez, eu e minhas colegas, funcionárias da biblioteca fomos também coadjuvantes deste triste episódio.

Quase sete horas... Eu em casa recebo uma ligação de uma colega da Secretaria da Educação, dizendo-me:
- Fica calma, mas vem para a biblioteca agora, pois o prédio está em chamas!

Troquei de roupa imediatamente, peguei meu carro e fui correndo para a biblioteca, que felizmente é a poucas quadras da minha casa. Ao chegar à rua, nem pude passar, pois os Bombeiros já tinham bloqueado a pista, para evitar estragos maiores.

Ao chegar em frente ao prédio, lembro-me como se fosse hoje, o meu desespero. Desatei a chorar. Chorar muito, ao ver tudo em chamas. $\mathrm{Eu}$ pensava no nosso trabalho de anos, parecia que eu estava perdendo um pedaço de mim, tamanha foi minha dor.

Eu quis entrar no prédio, fui impedida pelos Bombeiros, pois havia risco de explosão na parte superior do prédio. Portas foram arrombadas. Depois de um tempo solicitaramme as chaves das portas internas do prédio, aí acompanhei os Bombeiros na tentativa de evitar mais tragédias. Nós precisávamos deixar o ar circular dentro das salas, antes que o pior pudesse acontecer.

No terceiro andar do prédio tínhamos o Arquivo Histórico, ou seja, toda a história do nosso município, que hoje tem sessenta anos, poderia ir pelos ares.

Enquanto isso já estava pelos arredores, a imprensa, a polícia, funcionários $\mathrm{e}$ historiadores. Esses estavam tão preocupados e aflitos quanto nós. Afinal, documento queimado, jamais seria recuperado.

Ao chegar ao Porão, deparei-me com fogo ainda, eram muitos livros queimando, como vemos na Figura 21. Era uma cena desesperadora. 


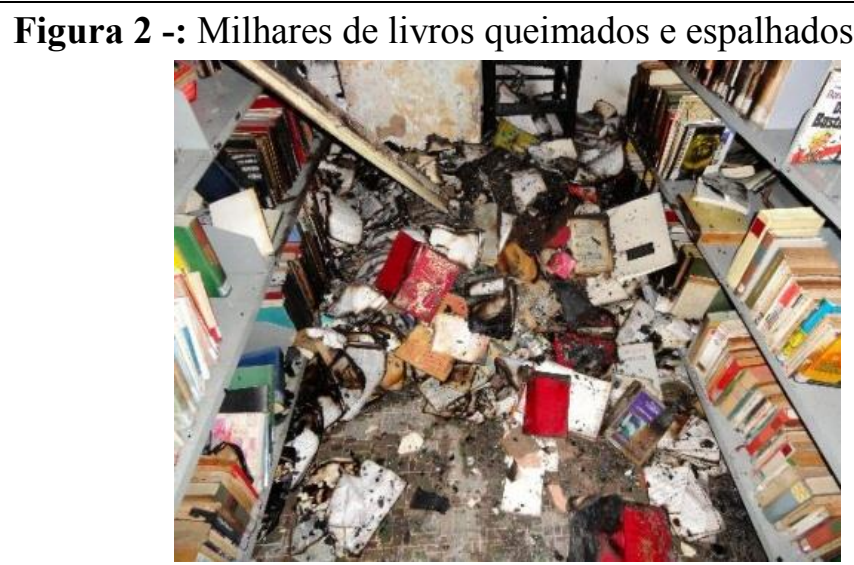

Fonte: Site Notícias R7

Não era possível pensar em nada, a não ser em chorarmos e nos lamentarmos pelo sinistro. Anos e anos de trabalho árduo ali, espalhados e carbonizados. A tristeza tomava conta dos nossos corações. A causa do incêndio, novamente foi um curto-circuito, no andar da
Câmara de Vereadores. Porém, desta vez, o estrago foi muito maior. Perdemos equipamento como computadores e telefones, conforme vemos na Figura 22.

Figura 22: Equipamentos derretidos após incêndio

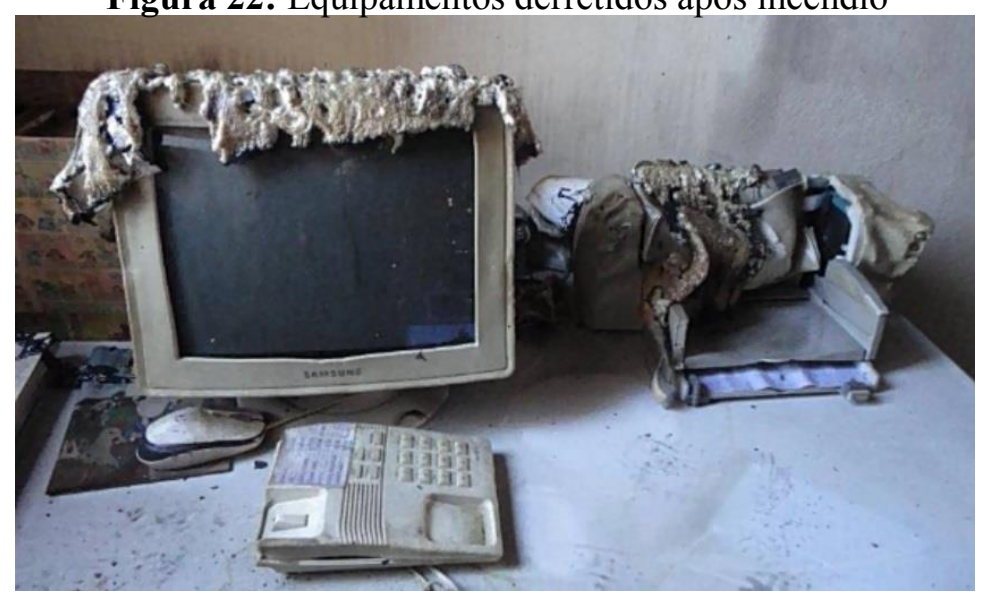

Fonte: Acervo Pessoal

O incêndio tomou uma proporção sem tamanho, pois atingiu três dos quatro andares

do prédio, conforme vemos na Figura 23.

Figura 23 - Assoalho do $1^{\circ}$ andar com visibilidade clara para as paredes do porão do prédio

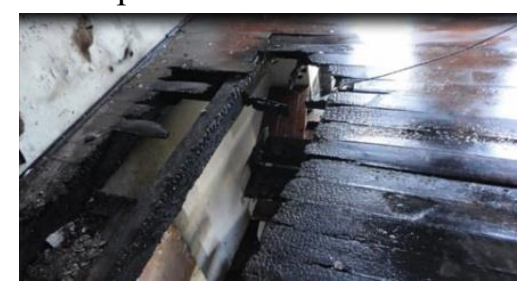

Fonte: Acervo Pessoal

Felizmente o último andar que mantinha o Arquivo Histórico Municipal não foi atingido pelo fogo. Este ficou apenas tomado por uma fuligem negra e com um cheiro muito ruim. 


\section{Relatos de Experiência}

Hoje ainda, ao manusear os documentos lá existentes, percebe-se a presença da fuligem, pois ela fica impregnada por onde passa.
Com essa tragédia foram perdidos, cerca de dezoito mil obras. Muitas de literatura, como vemos na Figura 24.

Figura 24: Imagem da sala de literatura, com milhares de obras queimadas.

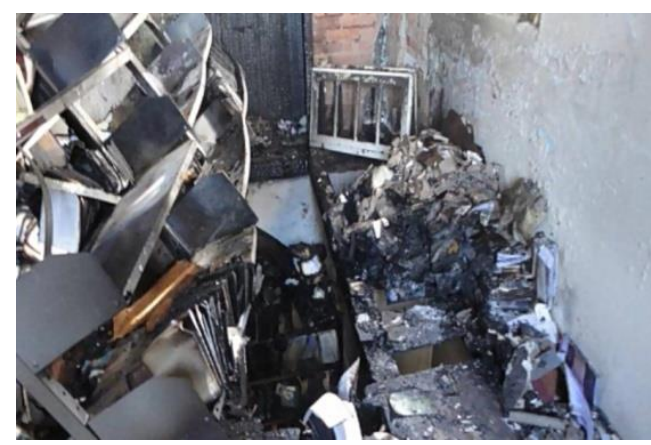

Fonte: Acervo Pessoal

Entre as obras perdidas, tínhamos literatura infantil, infantojuvenil, adulta e obras estrangeiras. Foi um fato muito triste, onde o fogo incontrolável acabava, a cada pouco, com a história da biblioteca. Depois deste sinistro a instituição ficou por meses e meses fechada para recuperação, tanto na parte estrutural, como na parte de acervo. Felizmente recebemos muitas doações, as quais hoje fazem parte do novo acervo da biblioteca, conforme nos mostram as Figuras 25, 26 e 27.

Figura 25: A solidariedade das pessoas doando livros

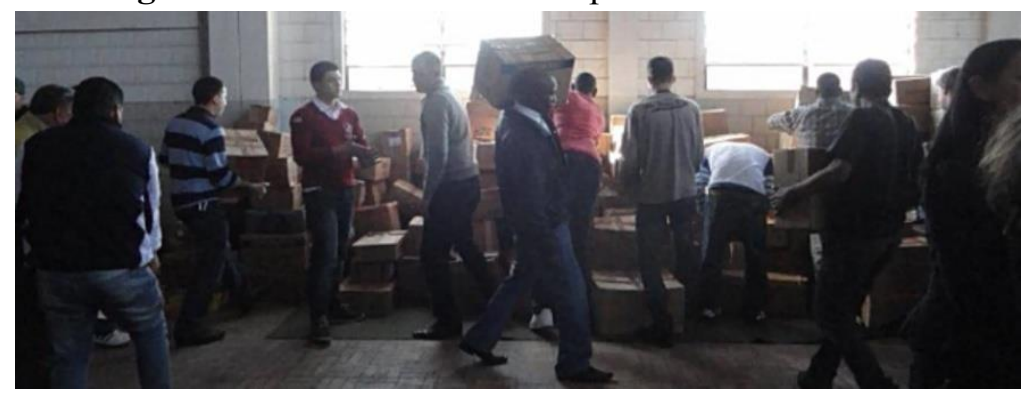

Fonte: Acervo Pessoal

Figuras 26 e 27: Milhares de doações foram recebidas

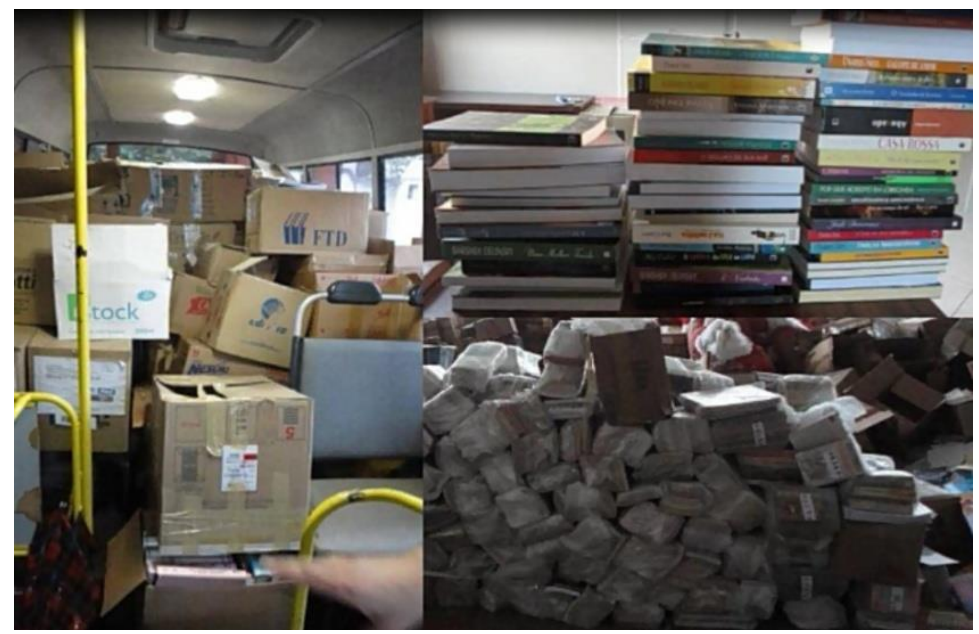

Fonte: Acervo Pessoal 
Relatos de Experiência

\section{CONSIDERAÇÕES FINAIS}

Entre chamas e lágrimas... é o que restava após um sinistro lamentável como o que aconteceu na Biblioteca Pública de Nova Petrópolis. Eram dezessete anos de funcionamento que víamos se destruindo ali, pouco a pouco. Mais de dezoito mil livros, periódicos, jornais, literatura infantil, obras raras e um acervo especial com quatorze idiomas diferentes. Destes, infelizmente, não restou nenhum "sobrevivente".

Foram meses de trabalho de funcionários e voluntários lavando paredes, recolhendo destroços e livros incendiados. E tudo isso em meio ao cheiro ruim de queimado, à sujeira da fuligem que ficou impregnada em tudo que restou e, em meio à dor de ver toda essa história queimada de forma tão brusca.

Mas, como diz o ditado, "depois da tempestade, vem à calmaria" ... E, depois de nove meses de árduo trabalho, com uma equipe reforçada de pessoas compromissadas e com o intuito de fazer o melhor... A "criança" como chamamos a "nova biblioteca", depois dos nove meses "gerados", nasceu, ou melhor, renasceu. E no dia 27 de fevereiro de 2012, como vemos na Figura 28, ao completar seus 18 anos, a Biblioteca Pública Municipal Prof ${ }^{a}$ Elsa Hofstätter da Silva reabriu suas portas para novamente poder atender a sua comunidade.

Figura 28 - Ato solene de reinauguração da Biblioteca Pública

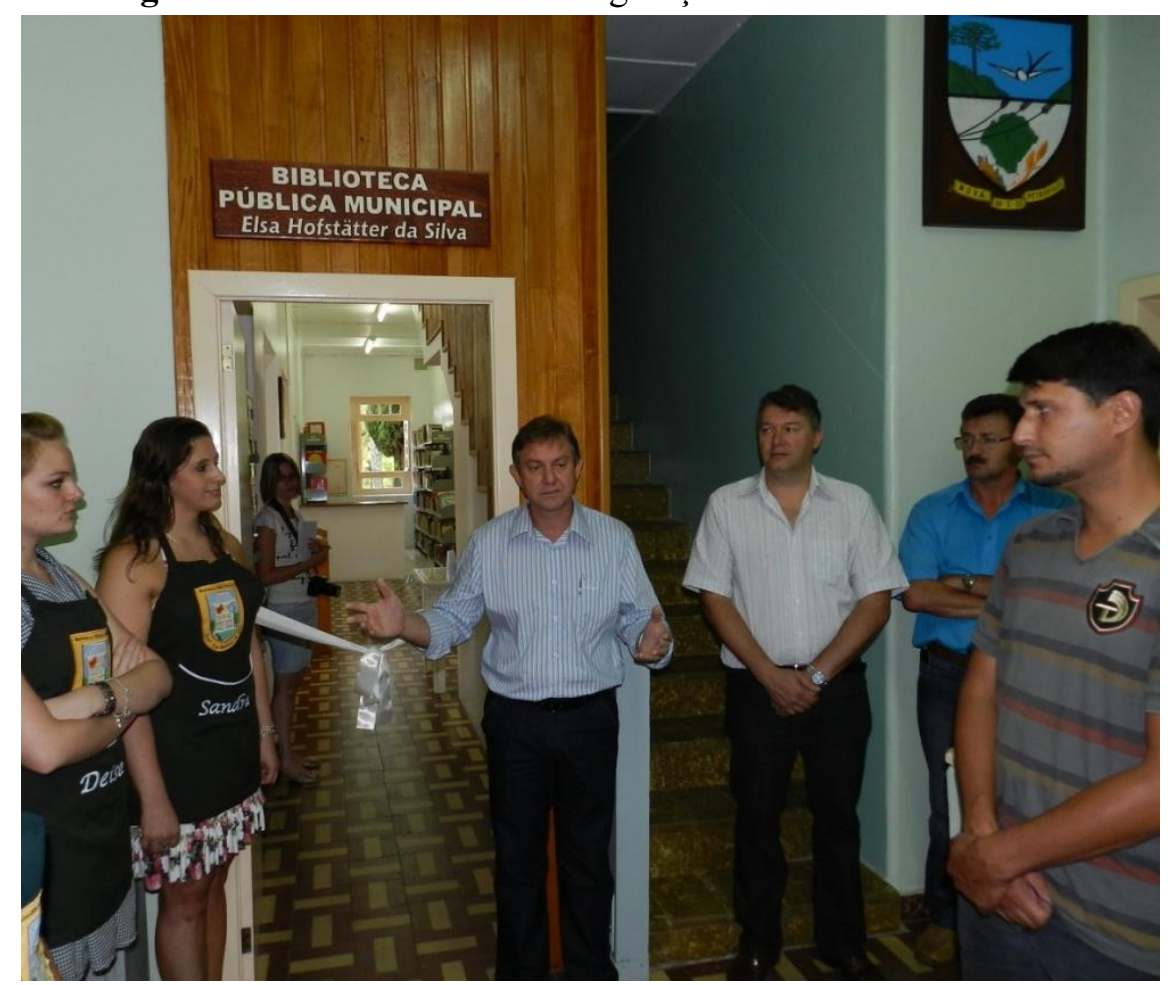

Foto: Imprensa da Prefeitura Municipal

Isso foi motivo de grande festa, com direito à torta e fita de reinauguração. Foi um momento muito esperado por todos que ali deixaram seu suor para contribuir para este reinício promissor.

Todo esse processo somente foi possível com a sensibilidade e o auxílio de muitas pessoas. A Secretaria da Educação, por exemplo, no período das férias escolares, colocou uma equipe de seis auxiliares de serviços gerais para nos ajudar no que fosse necessário. Essas ajudaram na organização, limpeza e inclusive na indexação e etiquetagem de livros novos.

A Secretaria de Obras nos auxiliou enviando seus funcionários para a limpeza mais pesada e para a organização do mobiliário. O Departamento de Transportes da Prefeitura efetuou o transporte de milhares e milhares de livros que vieram de doação para a biblioteca. Nossa gratidão também foi aos Bombeiros Voluntários de Nova Petrópolis que prontamente estiveram lá no momento do incêndio, fazendo o mais rápido possível o seu trabalho, evitando desta forma, que o fogo se espalhasse mais. 
Enfim, todos deram o seu melhor para que tudo fosse reconstruído de maneira a atender brevemente o público que utilizava a biblioteca.

Assim, de um curto-circuito que muito destruiu, ficou a certeza que, mesmo difícil e dolorido, é possível recomeçar, através de boas ações, solidariedade e principalmente com cumplicidade e companheirismo entre os envolvidos nesta nobre causa. Pois essa foi a base fundamental para este recomeço, onde tivemos uma verdadeira conquista com a união e cooperação de todos. Desta forma que a Biblioteca Pública Prof ${ }^{a}$ Elsa Hofstätter da Silva reconstruiu sua história e hoje atende normalmente seus usuários.

\title{
BETWEEN FLAMES AND TEARS: THE REALITY OF A LIBRARY
}

\begin{abstract}
This assignment aim to show the reality of the functioning of Prof ${ }^{a}$ Elsa Hofstätter da Silva Public Library in Nova Petrópolis. It will be presented the available services, the developed activities, the content of the collection and the work of the professionals in the institution. This non-profit library was created in 1990 and received this name in honor to Dona Elsa, writer of Nova Petrópolis's anthem, poet and dramatist. It had about 25 thousand registered books. Were included in this collection many literary genres, youth literature collections, special collections written in foreign languages, updated newspapers besides local and regional newspapers, and comic books. The library has four thousand and seven hundred readers registered. In 2011, the library went through a fire that affected its fisical structure and its collection, resulting in an immesurable loss.
\end{abstract}

Keywords: Library. Collection. Fire.

\section{REFERÊNCIAS}

ALMEIDA JR., Oswaldo Francisco de. Biblioteca pública: avaliação de serviços. Londrina: EDUEL, 2003. 288 p.

\section{BIBLIOTECA NACIONAL}

(BRASIL). Biblioteca pública: princípios e

diretrizes. Rio de Janeiro: Fundação

Biblioteca Nacional, 2000. 160 p.

FREIRE, Paulo. Pedagogia da

autonomia: saberes necessários à prática educativa. 23.ed. São Paulo: Paz e Terra, 2002. $165 \mathrm{p}$.

INFORMAÇÕES do Software Pergamum: Disponível em:

$<$ http://www.pergamum.pucpr.br/redepergam um/rede_conheca.php?ind $=1>$. Acesso em 22 jun. $201 \overline{5}$.

NOTÍCIAS da Biblioteca Pública: Disponível em:

$<$ http://www.novapetropolis.com.br/int_notici as.php?id $=970 \&$ tipo $=4>$. Acesso em 22 jun. 2015.
NOVA PETRÓPOLIS/RS. LEI n ${ }^{\circ}$ 655/1979:

Disponível em:

$<$ http://www.cespro.com.br/visualizarDiplom a.php?cdMunicipio $=7699 \&$ cdDiploma $=655$

lei $655>$. Acesso em 22 jun. 2015.

NOVA PETRÓPOLIS/RS. LEI $n^{\circ}$

1.192/1990: Disponível em:

$<$ http://novapetropolis.cespro.com.br/ lei 1990>. Acesso em 22 jun. 2015. 